\title{
ChemComm
}

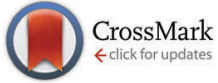

Cite this: Chem. Commun., 2017. 53,2729

Received 23rd January 2017, Accepted 7th February 2017

DOI: 10.1039/c7cc00656j rsc.li/chemcomm

\section{Rigidly linking cyclometallated Ir(III) and Pt(II) centres: an efficient approach to strongly absorbing and highly phosphorescent red emitters $\dagger$}

\author{
Graeme Turnbull, ${ }^{a}$ J. A. Gareth Williams*b and Valery N. Kozhevnikov*a
}

\begin{abstract}
The synthesis and photophysical properties of an unprecedented tetranuclear complex are described, in which a fac-tris-cyclometallated Ir(III) centre is rigidly connected to three cyclometallated $\mathrm{Pt}($ II) centres. The complex absorbs strongly up to $\sim 600 \mathrm{~nm}$ and emits red light with unusually high efficiency.
\end{abstract}

Phosphorescent metal complexes that emit light with high efficiency are being explored for a variety of applications. For example, some are used as phosphors in commercial organic light-emitting diodes (OLEDs), whilst ionic variants are under investigation for light-emitting electrochemical cells (LEECs). ${ }^{1,2}$ Meanwhile, their relatively long luminescence lifetimes and good photostability have rendered them of interest as probes for bioimaging, ${ }^{3}$ particularly for time-resolved detection procedures, ${ }^{4}$ and for sensing of biologically and environmentally relevant analytes such as metal ions, molecular oxygen and organic vapours. ${ }^{5,6}$ The most successful complexes have tended to be based around cyclometallated iridium complexes, where the high spin-orbit coupling associated with a 3rd-row metal ion in a pseudooctahedral geometry typically ensures that the formally forbidden $\mathrm{T}_{1} \rightarrow \mathrm{S}_{0}$ phosphorescence is promoted effectively. ${ }^{7}$ The brightest such emitters emit in the green region of the spectrum; e.g., the archetypal complex $f a c$-Ir(ppy) ${ }_{3}$ emits in degassed solution ${ }^{8}$ with a $\lambda_{\text {max }}$ of $508 \mathrm{~nm}$ and a photo-luminescence quantum yield recently re-assessed to be $0.97 . \ddagger^{8 c}$

Strategies for shifting the emission of this family of compounds to the red and near-infrared rely on increasing the conjugation within the ligands, and/or on the use of more electron-rich cyclometallating rings (e.g. thienyl in place of phenyl). ${ }^{9,10}$ Whilst such methods do lead to desired red shifts, efficiencies invariably fall off compared to green emitters, owing to the combined effects

\footnotetext{
${ }^{a}$ Department of Applied Sciences, Northumbria University, Newcastle upon Tyne, NE1 8ST, UK. E-mail: valery.kozhevnikov@northumbria.ac.uk

${ }^{b}$ Department of Chemistry, Durham University, South Road, Durham, DH1 3LE, UK. E-mail: j.a.g.williams@durham.ac.uk

$\dagger$ Electronic supplementary information (ESI) available: Synthetic methods, compound characterisation, TD-DFT and electrochemical data. See DOI: 10.1039/c7cc00656j
}

of increased non-radiative decay of lower-energy excited states, and the decrease in radiative rate constants. The latter effect can be understood not only in terms of the $\nu^{3}$ term within the Einstein coefficient for spontaneous emission (which affects all emitters) but also through the fact that the extent of participation of the metal in the excited state necessarily decreases as the ligands become more electron rich and/or the conjugation increases. The effect may even be manifest through such complexes displaying fluorescence from the singlet excited state, in competition with triplet state formation and subsequent phosphorescence. ${ }^{10}$

We have recently shown how the introduction of a second iridium centre to generate dinuclear complexes can lead to efficient red emitters that display unusually high triplet radiative decay rates, $k_{\mathrm{r}}$, and hence high phosphorescence quantum yields. ${ }^{11}$ The complexes feature two iridium ions each bound to a common, bridging heterocyclic ring, such as a pyrimidine, within a bi- or tridentate ligand. Similar results were found for related dinuclear platinum complexes, whose emission was red-shifted and $k_{\mathrm{r}}$ values increased relative to mononuclear analogues. ${ }^{12}$

Given the importance of $f a c$ - $\operatorname{Ir}(\mathrm{ppy})_{3}$ in the field, we have now sought to modify this archetypal complex in such a way that a $\mathrm{Pt}(\mathrm{II})$ ion is introduced into each ligand, to generate an unprecedented heterometallic tetranuclear complex, 1 (Fig. 1).

Our strategy relies on the use of 4,6-bis-(4-t-butylphenyl)pyrimidine $\left(\right.$ bppym $\left.\mathrm{H}_{2}\right)$ as a bis- $\mathrm{N}^{\wedge} \mathrm{C}$-coordinating ligand that can bind simultaneously to two metal ions through cyclometallation. ${ }^{12 a}$ tert-Butyl substituents were included in the para positions of the phenyl rings, in order to improve the solubility of the final complexes.

The target complex $\operatorname{Ir}\{(\mu \text {-bppym)Pt(acac })\}_{3} 1$ was obtained in two steps (Scheme 1). Owing to the harsh conditions required for the preparation of fac tris-cyclometallated Ir(III) complexes, we chose to incorporate the iridium centre first, to be followed by the introduction of the platinum ions. The fac tris-cyclometallated complex $\operatorname{Ir}(\text { bppymH })_{3} 2$ was initially obtained in 30\% yield from the corresponding bis-cyclometallated complex $\operatorname{Ir}(\mathrm{bppymH})_{2}(\mathrm{acac})$ 3 upon reaction with bppym $\mathrm{H}_{2}$ in glycerol at $200{ }^{\circ} \mathrm{C}$, ESI. $\dagger$ Compound $\mathbf{3}$ is itself prepared through the intermediacy of 


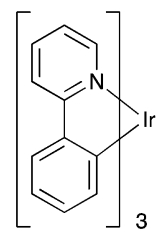

$\operatorname{Ir}(\mathrm{ppy})_{3}$

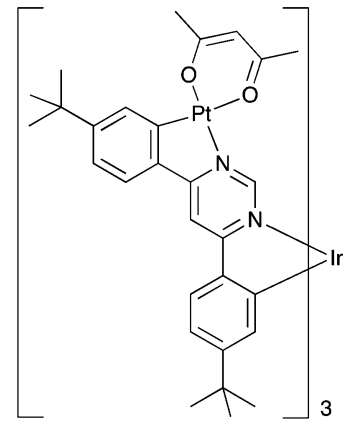

Complex 1
Fig. 1 Structures of $\operatorname{Ir}(\mathrm{ppy})_{3}$ and of the heterometallic tetranuclear complex 1.

$\left[\operatorname{Ir}(\text { bppymH })_{2}(\mu-\mathrm{Cl})\right]_{2}$, obtained upon reaction of bppymH $\mathrm{H}_{2}$ with $\mathrm{IrCl}_{3} \cdot 3 \mathrm{H}_{2} \mathrm{O}$ in a $2: 1$ molar ratio, followed by treatment with sodium acetylacetonate. An alternative, more direct and higheryielding synthesis of 2 proved to be the reaction of bppymH $\mathrm{H}_{2}$ with $\operatorname{Ir}(\mathrm{acac})_{3}$ in the presence of $o$-phosphoric acid, which gave the product in $52 \%$ yield after column chromatography.

The mononuclear complex 2 was then reacted with $\mathrm{K}_{2} \mathrm{PtCl}_{4}$ (3.75 equiv.) in a mixture of acetic acid and acetonitrile at reflux, followed by treatment of the resulting solid with an excess of sodium acetylacetonate in acetone, leading to the target tetranuclear complex 1 in $6 \%$ yield. The low yield may be related to the need for a total of three such metallations and subsequent chloride metatheses to occur.§ The fac geometry around the Ir centre ensures that the three Pt units are able to be accommodated on one side of the molecule without excessive steric hindrance, despite the large size and apparently congested nature of the molecule. Molecular mechanics and DFT calculations confirm that the structure is feasible, with the distances between neighbouring ligands being no shorter than van der Waals contacts (see ESI, $\dagger$ including Fig. S2.1 for 3D views of the molecule).

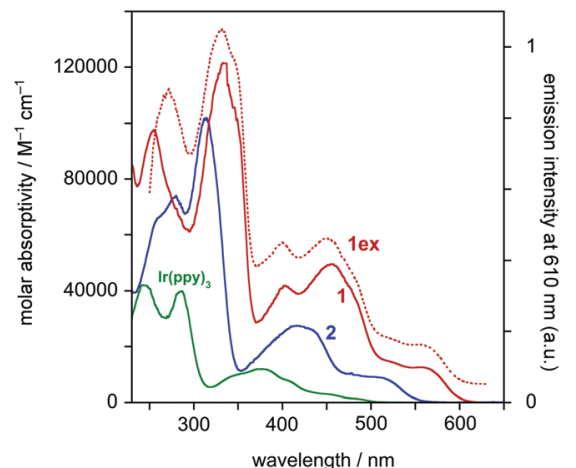

Fig. 2 Absorption spectra of 1 (red solid line), 2 (blue) and fac-Ir(ppy) (green) in $\mathrm{CH}_{2} \mathrm{Cl}_{2}$ at $298 \pm 3 \mathrm{~K}$. The excitation spectrum of 1 under the same conditions, registered at $\lambda_{\mathrm{em}}=610 \mathrm{~nm}$, is the red dotted line labelled $1 \mathrm{ex}$.

The UV-visible absorption spectrum of the new tetranuclear complex $\mathbf{1}$ in dichloromethane solution at room temperature is shown in Fig. 2, together with the spectra of the mononuclear complex 2 as a model and of $f a c-\operatorname{Ir}(\mathrm{ppy})_{3}$. Corresponding data are provided in Table 1. It can be seen that the absorption of complex 1 is strongly red-shifted compared to $f a c-\operatorname{Ir}(\mathrm{ppy})_{3}$ - by around $4500 \mathrm{~cm}^{-1}$ for most of the bands - and that the extinction coefficients are greatly increased, by a factor of around 4 , throughout the spectrum. By reference to the model complex 2 , it is evident that one contributing factor in generating these effects is the change from a pyridine to a pyrimidine ring in the $\mathrm{N}^{\wedge} \mathrm{C}$-cyclometallating ligand. This is readily rationalised since the lowest-energy transitions in $\operatorname{Ir}\left(\mathrm{N}^{\wedge} \mathrm{C}\right)_{3}$ complexes are normally associated with charge-transfer transitions in which the heterocyclic ring is the acceptor. ${ }^{1 c, 9,13}$ However, the introduction of the $\mathrm{Pt}(\mathrm{II})$ centres onto the second $\mathrm{N}^{\wedge} \mathrm{C}$ unit of each ligand leads to a further significant red shift of the bands in the visible region - and indeed also in the UV - of around $2000 \mathrm{~cm}^{-1}$. Moreover, the molar absorptivity is further increased; for example, $\varepsilon$ for the most intense band in the visible region of each complex is increased by a factor of 2

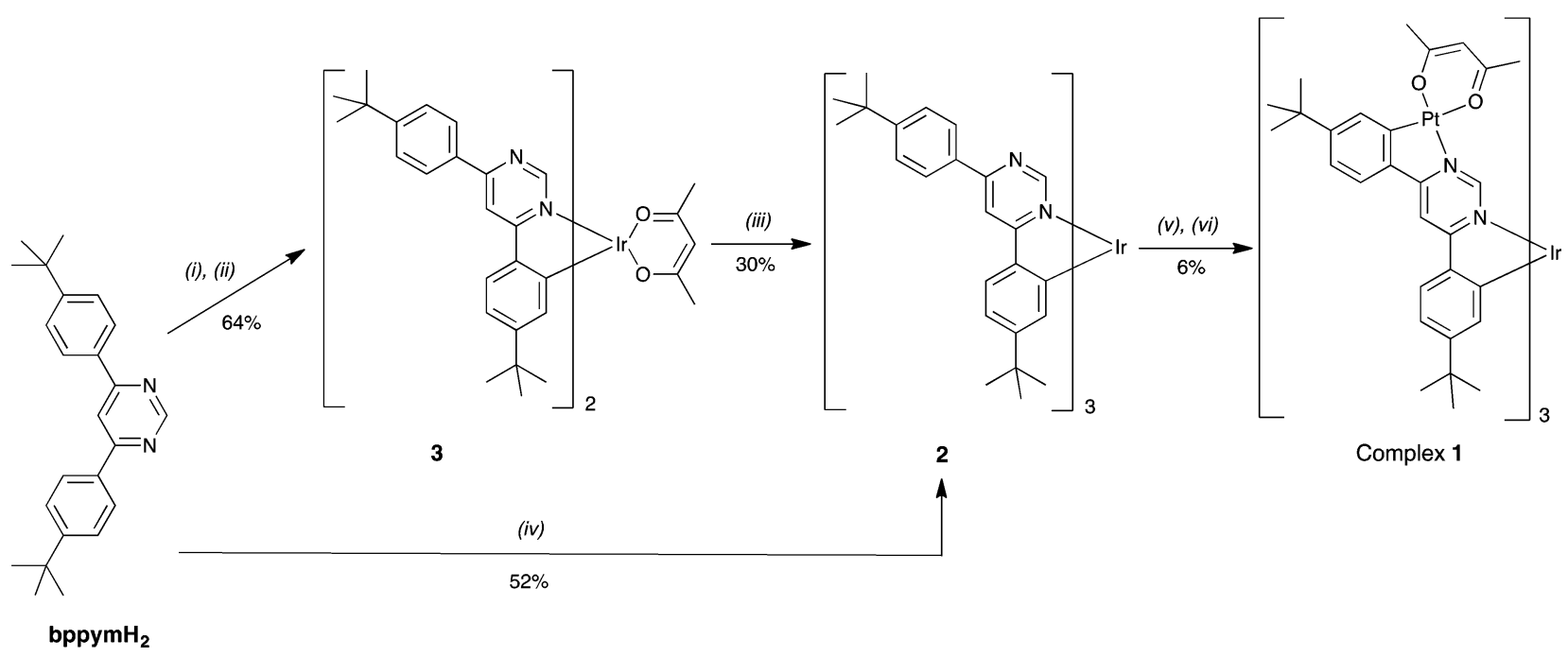

Scheme 1 Routes to 1 starting from bppymH $\mathrm{H}_{2}$ : (i) $\operatorname{IrCl}_{3} \cdot 3 \mathrm{H}_{2} \mathrm{O}\left(0.5\right.$ equiv.), ethoxyethanol, $110{ }^{\circ} \mathrm{C}, 14 \mathrm{~h}$. (ii) $\mathrm{Na}(\mathrm{acac}), 90{ }^{\circ} \mathrm{C}, 5 \mathrm{~h}$. (iii) bppymH $\mathrm{H}_{2}, \mathrm{glycerol}$, $200{ }^{\circ} \mathrm{C}, 2$ h. (iv) $\operatorname{Ir}(\mathrm{acac})_{3}\left(0.28\right.$ equiv.), $\mathrm{H}_{3} \mathrm{PO}_{4}$, glycerol, $190{ }^{\circ} \mathrm{C}, 18 \mathrm{~h}$. (v) $\mathrm{K}_{2} \mathrm{PtCl}_{4}$ (>3 equiv.), $\mathrm{AcOH} / \mathrm{MeCN}, 36 \mathrm{~h}$. (vi) Na(acac), acetone, reflux, $10 \mathrm{~h}$. 
Table 1 Photophysical properties of the heterometallic tetranuclear complex 1, the model mononuclear iridium complex 2, and fac-Ir(ppy) for comparison. Data refer to solutions in $\mathrm{CH}_{2} \mathrm{Cl}_{2}$ at $298 \pm 3 \mathrm{~K}$ except where stated otherwise

\begin{tabular}{|c|c|c|c|c|c|c|c|c|c|}
\hline Complex & $\begin{array}{l}\text { Absorption }^{a} \\
\lambda_{\text {max }} / \mathrm{nm}\left(\varepsilon / 10^{3} \mathrm{M}^{-1} \mathrm{~cm}^{-1}\right)\end{array}$ & $\frac{\text { Emission }}{\lambda_{\max } / \mathrm{nm}}$ & $\Phi_{\text {lum }}^{b, c}$ & $\tau^{d} / \mathrm{ns}$ & $k_{\mathrm{r}}^{e} / 10^{5} \mathrm{~s}^{-1}$ & $\sum k_{\mathrm{nr}}^{e} / 10^{5} \mathrm{~s}^{-1}$ & $k_{\mathrm{Q}}^{\mathrm{O}_{2} f} / 10^{8} \mathrm{M}^{-1} \mathrm{~s}^{-1}$ & \multicolumn{2}{|c|}{ Emission at $77 \mathrm{~K}^{g}$} \\
\hline 1 & $\begin{array}{l}255 \text { (97.7), } 334 \text { (121), } 404 \text { (41.6), } \\
455 \text { (49.6), } 554 \text { (12.5) }\end{array}$ & 611 & 0.76 & $720[300]$ & 11 & 3.3 & 8.8 & 586,635 & 2600 \\
\hline 2 & $\begin{array}{l}\text { 260sh (66.0), } 279(73.5), 313 \text { (102), } \\
416(27.5), 506(9.15)\end{array}$ & 590 & 0.61 & $1400[200]$ & 4.4 & 2.8 & 19 & 556,593 & 3900 \\
\hline $\operatorname{Ir}(\mathbf{p p y})_{3}^{h, i, j}$ & $\begin{array}{l}283(44.8), 341(9.2), 377(12.0), \\
405(8.1), 455(2.8), 488(1.6)\end{array}$ & 508 & 0.97 & $1600[36]$ & 6.1 & 0.2 & - & 491 & 4000 \\
\hline
\end{tabular}

${ }^{a}$ Bands of $\lambda>250 \mathrm{~nm}$ are listed. ${ }^{b}$ In degassed solution. ${ }^{c}$ Luminescence quantum yield measured for 1 and 2 using $\left[\mathrm{Ru}(\mathrm{bpy})_{3}\right] \mathrm{Cl}{ }_{2}$ as the standard. ${ }^{d}$ In degassed solution for 1 and 2, under nitrogen for $\operatorname{Ir}(\mathrm{ppy})_{3}$; values in air-equilibrated solution are shown in parenthesis. ${ }^{e} k_{\mathrm{r}}$ and $\sum k_{\mathrm{nr}}$ are the radiative and non-radiative rate constants estimated according to: $k_{\mathrm{r}}=\Phi_{\text {lum }} / \tau$ and $k_{\mathrm{nr}}=\left(1-\Phi_{\mathrm{lum}}\right) / \tau .{ }^{f}$ Bimolecular rate constant for quenching by molecular oxygen, estimated from the $\tau$ values in degassed and air-equilibrated solution, and assuming $\left[\mathrm{O}_{2}\right]=2.2 \mathrm{mM}$ in $\mathrm{CH}_{2} \mathrm{Cl}_{2}$ at atmospheric pressure of air. ${ }^{g}$ Data for 1 and 2 at $77 \mathrm{~K}$ are in a glass of diethyl ether/isopentane/ethanol, 2:2:1 v/v. ${ }^{h}$ Data refer to the fac isomer of $\operatorname{Ir}(\text { ppy })_{3} .{ }^{i}$ Absorption data for $\operatorname{Ir}(\text { ppy })_{3}$ in $\mathrm{CH}_{2} \mathrm{Cl}_{2}$, from ref. $8 b .{ }^{j}$ Emission data for Ir(ppy) ${ }_{3}$ are in 2-MeTHF except for $\tau$ in air-equilibrated solution, which is in toluene; no $k_{\mathrm{Q}}$ value is therefore given; data from ref. $8 c . \Phi_{\text {lum }}$ was reported in ref. $8 a$ and $b$ to be 0.40 .

(for complex 1, $\lambda_{\max }=455 \mathrm{~nm}, \varepsilon=49600 \mathrm{M}^{-1} \mathrm{~cm}^{-1}$; for complex 2, $\lambda_{\max }=416 \mathrm{~nm}, \varepsilon=27500 \mathrm{M}^{-1} \mathrm{~cm}^{-1}$ ). It may be noted that there are no bands with $\varepsilon>10000 \mathrm{M}^{-1} \mathrm{~cm}^{-1}$ in the visible region for $f a c-\operatorname{Ir}(\mathrm{ppy})_{3}$.

TD-DFT calculations confirm the observed red-shift in the lowest-energy absorption bands in $\mathbf{1}$ compared to $\mathbf{2}$ (see ESI $\dagger$ ), and suggest that the effect upon introduction of the platinum centres is due to a stabilisation of the LUMO that exceeds that of the HOMO. Thus, the LUMO energies of $\mathbf{1}$ and 2 are calculated to be -1.90 and $-2.27 \mathrm{eV}$ respectively (a stabilisation of $0.37 \mathrm{eV}$ ), whilst the HOMO values are -5.12 and $-5.34 \mathrm{~V}$ (stabilisation of $0.22 \mathrm{eV}$ ). A large stabilisation of the LUMO upon platination is confirmed by cyclic voltammetry (see Fig. S3.1 of the ESI $\dagger$ ). Complex 1 shows a first reduction at $-2.22 \mathrm{~V}$ (in $\mathrm{CH}_{2} \mathrm{Cl}_{2}$ versus ferrocene) whereas 2 , in common with complexes like $\operatorname{Ir}(\mathrm{ppy})_{3}$, shows no reduction within the accessible window (the region down to $-3 \mathrm{~V}$ in $\mathrm{CH}_{2} \mathrm{Cl}_{2}$ was probed). The first oxidation, in contrast, is shifted by $<0.3 \mathrm{~V}$.

Complex 1 is intensely luminescent in solution at room temperature, emitting in the red region of the spectrum; $\lambda_{\max }=611 \mathrm{~nm}$ (Fig. 3 and Table 1). The luminescence quantum yield of 0.76 renders it one of the very brightest red-emitting molecular phosphors reported. ${ }^{9}$ The emission is strongly redshifted compared to $f a c-\operatorname{Ir}(\mathrm{ppy})_{3}$ by over $3000 \mathrm{~cm}^{-1}$, though the shift in $\lambda_{\max }$ relative to 2 is only around $500 \mathrm{~cm}^{-1}$ at room temperature (around $1000 \mathrm{~cm}^{-1}$ at $77 \mathrm{~K}$ ). Inspection of the roomtemperature spectra reveals that the polynuclear complex displays a narrower profile than that of the mononuclear model under these conditions (half-height widths of 2170 and $2860 \mathrm{~cm}^{-1}$ respectively). Meanwhile, the Stokes shift between the lowestenergy absorption band and the peak of the emission band is significantly smaller for the polynuclear system (around $1600 \mathrm{~cm}^{-1}$ for 1 compared to $2800 \mathrm{~cm}^{-1}$ for 2 ). Both observations are suggestive of the polynuclear system being more rigid and subject to less excited-state distortion. It is notable that, at $77 \mathrm{~K}$, the ratio of the intensity of the 0,0 to 0,1 vibrational components is higher for $\mathbf{1}$ than for $\mathbf{2}$, an observation that also suggests less excited-state distortion for $1 .{ }^{14}$ The luminescence lifetime $\tau$ of complex $\mathbf{1}$ is $720 \mathrm{~ns}$ at room temperature, an

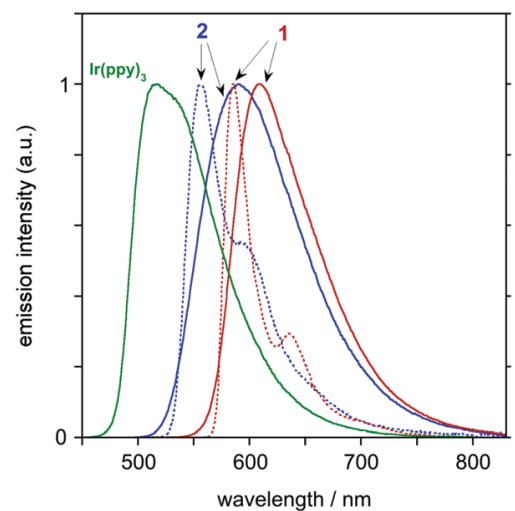

Fig. 3 Emission spectra of 1, 2 and fac- $\operatorname{lr}(\mathrm{ppy})_{3}$ in $\mathrm{CH}_{2} \mathrm{Cl}_{2}$ at $298 \pm 3 \mathrm{~K}$ (red, blue and green solid lines respectively), together with the spectra of 1 and 2 at $77 \mathrm{~K}$ in diethyl ether/isopentane/ethanol $(2: 2: 1 \mathrm{v} / \mathrm{v})$.

unusually short lifetime for cyclometallated iridium complexes (e.g., for $f a c-\operatorname{Ir}(\mathrm{ppy})_{3}, \tau=1.9 \mu \mathrm{s}$ under comparable conditions) yet the luminescence quantum yield remains high. The short lifetime is thus indicative of an unusually fast radiative decay rate $k_{\mathrm{r}}$ (as opposed to deleterious non-radiative decay). Assuming that the emitting state is formed with unitary efficiency upon light absorption, $k_{\mathrm{r}}$ can be estimated from $\tau$ and $\Phi_{\text {lum }}$ to be $11 \times 10^{5} \mathrm{~s}^{-1}$, which is double that of $f a c$-Ir(ppy) ${ }_{3}$. The substantial augmentation of $k_{\mathrm{r}}$ is consistent with the effect of additional metal ions in polynuclear systems we have investigated previously. ${ }^{11,12}$ Whilst it may be tempting to attribute the effect to enhanced spin-orbit coupling associated with the presence of the additional metal ions, the fact that the spin-allowed bands in absorption are also significantly increased in intensity (higher $\varepsilon$ values in the polynuclear system) suggests that there may be other factors at work in increasing oscillator strengths.

Complex $\mathbf{1}$ is much less sensitive to quenching by dissolved molecular oxygen than typical iridium-based emitters; e.g., $\tau$ and $\Phi_{\text {lum }}$ are decreased by a factor of only 2 upon aeration \{which compares with 7 -fold for 2 and around 13-fold for $\left.f a c-\operatorname{Ir}(\mathrm{ppy})_{3}\right\}$. The lower sensitivity to quenching can be attributed not only to the shorter lifetime, but also to a smaller value of the bimolecular 
rate constant for quenching, $k_{\mathrm{Q}}$ (Table 1 ). This in turn may be associated, at least in part, with the substantially larger molecular weight of the polynuclear complex. $\uparrow$

In summary, the preparation of the new heterometallic tetranuclear complex demonstrates how the introduction of additional heavy metal ions can allow access to phosphorescent molecules that (i) emit with higher efficiency in the red region of the spectrum with narrower spectral profiles, and (ii) absorb out to longer wavelengths and with substantially higher extinction coefficients than conventional mononuclear systems. Point (i) arises from an increase in radiative rate constants associated with the additional metal ions, a trend that is emerging from homodinuclear systems too. ${ }^{11,12}$ However, in the present instance at least, it may also be related to an increase in the rigidity of the system, helping to minimise excited state distortion and hence reduce competitive non-radiative decay. High rigidity also leads to the narrow spectral profile, important for colour purity in display screen applications. These observations point a way for the development of more efficient red and NIR molecular emitters.

Meanwhile, point (ii) is potentially important with regards to the use of iridium complexes for solar energy conversion and photocatalysis, for example, where more efficient absorption across the visible region of the spectrum is desirable for practicable application. ${ }^{15}$ Finally, we note that the combination of efficient low-energy [red] absorption and low-energy [red/NIR] emission is a key desirable criterion for bioimaging applications, to exploit the "window of transparency" of biological tissue in this region of the spectrum.,

Complex 1 may be regarded as a metallodendrimer of firstgeneration type, where the cyclometallated Pt(II) shell surrounds the central fac-tris-cyclometallated Ir(III) core. Many other such multinuclear complexes can be envisaged that may offer attractive optical or opto-catalytic properties.

We thank Melissa Walden, Emma Puttock and Dr Marcus Durrant for their valued input, and the Universities of Northumbria and Durham for support.

\section{Notes and references}

\$ In deoxygenated 2-MeTHF at $298 \mathrm{~K}$.

$\S$ The synthesis and isolation of the corresponding trinuclear $\left(\mathrm{Pt}_{2} \mathrm{Ir}\right)$ and dinuclear (PtIr) complexes has been attempted, using ratios of $\mathrm{K}_{2} \mathrm{PtCl}_{4}$ to complex 2 of proportionately less than $3: 1$. Whilst ${ }^{1} \mathrm{H}$ NMR and MS data did imply the formation of these species (and hence that the formation of $\mathbf{1}$ from $\mathbf{2}$ likely proceeds via mono- and bis-platinated intermediates), it has not proved possible to isolate pure samples, apparently due to their co-elution under a variety of chromatographic conditions.

I According to the Smoluchowski equation, $k_{\mathrm{Q}}^{\mathrm{O}_{2}}$ is proportional to the diffusion coefficient, which is in turn proportional to $\sqrt{ }$ MW through Fick's Law. The MW values of 1 and 2 are 2100 and 1221 respectively.
1 (a) Highly Efficient OLEDs with Phosphorescent Materials, ed. H. Yersin, Wiley-VCH, Weinheim, Germany, 2007; (b) Y. Chi and P. T. Chou, Chem. Soc. Rev., 2010, 39, 638; (c) L. F. Gildea and J. A. G. Williams, Iridium and platinum complexes for OLEDs, in Organic Light-Emitting Diodes: Materials, Devices and Applications, ed. A. Buckley, Woodhead, Cambridge, 2013; (d) E. Baranoff and B. F. E. Curchod, Dalton Trans., 2015, 44, 8318.

2 (a) R. D. Costa, E. Ortí, H. J. Bolink, F. Monti, G. Accorsi and N. Armaroli, Angew. Chem., Int. Ed., 2012, 51, 8178; (b) S. Ladouceur and E. Zysman-Colman, Eur. J. Inorg. Chem., 2013, 2985.

3 (a) E. Baggaley, J. A. Weinstein and J. A. G. Williams, Coord. Chem. Rev., 2012, 256, 1762; (b) K. K.-W. Lo and S. P.-Y. Li, RSC Adv., 2014, 4, 10560; (c) M. P. Coogan and V. Fernández-Moreira, Chem. Commun., 2014, 50, 384; (d) Z. Q. Guo, W.-L. Tong and M. C. W. Chan, Chem. Commun., 2014, 50, 1711.

4 (a) E. Baggaley, S. W. Botchway, J. W. Haycock, H. Morris, I. V. Sazanovich, J. A. G. Williams and J. A. Weinstein, Chem. Sci., 2014, 5, 879; (b) E. Baggaley, J. A. Weinstein and J. A. G. Williams, Struct. Bonding, 2015, 165, 205.

5 (a) Q. Zhao, F. Li and C. Huang, Chem. Soc. Rev., 2010, 39, 3007; (b) Y. You, S. Cho and W. Nam, Inorg. Chem., 2014, 53, 1804.

6 (a) X.-D. Wang and O. S. Wolfbeis, Chem. Soc. Rev., 2014, 43, 3666; (b) T. Yoshihara, Y. Yamaguchi, M. Hosaka, T. Takeuchi and S. Tobita, Angew. Chem., Int. Ed., 2012, 51, 4148; (c) J. R. Berenguer, J. Fernandez, B. Gil, E. Lalinde and S. Sanchez, Chem. - Eur. J., 2014, 20, 2574.

7 H. Yersin, A. F. Rausch, R. Czerwieniec, T. Hofbeck and T. Fischer, Coord. Chem. Rev., 2011, 255, 2622.

8 (a) K. A. King, P. J. Spellane and R. J. Watts, J. Am. Chem. Soc., 1985, 107, 1431; (b) A. B. Tamayo, B. D. Alleyne, P. I. Djurovich, S. Lamansky, I. Tsyba, N. M. Ho, R. Bau and M. E. Thompson, J. Am. Chem. Soc., 2003, 125, 7377; (c) T. Sajato, P. I. Djurovich, A. B. Tamayo, J. Oxgaard, W. A. Goddard III and M. E. Thompson, J. Am. Chem. Soc., 2009, 131, 9813.

9 (a) S. Lamansky, P. Djurovich, D. Murphy, F. Abdel-Razzaq, H. E. Lee, C. Adachi, P. E. Burrows, S. R. Forrest and M. E. Thompson, J. Am. Chem. Soc., 2001, 123, 4304; (b) A. Tsuboyama, H. Iwawaki, M. Furugori, T. Mukaide, J. Kamatani, S. Igawa, T. Moriyama, S. Miura, T. Takiguchi, S. Okada, M. Hoshini and K. Ueno, J. Am. Chem. Soc., 2003, 125, 12971; (c) Y. J. Su, H. L. Huang, C. L. Li, C. H. Chien, Y. T. Tao, P. T. Chou, S. Datta and R. S. Liu, Adv. Mater., $2003,15,224 ;(d)$ F. M. Hwang, H. Y. Chen, P. S. Chen, C. S. Liu, Y. Chi, C. F. Shu, F. I. Wu, P. T. Chou, S. M. Peng and G. H. Lee, Inorg. Chem., 2005, 44, 1344.

10 (a) D. N. Kozhevnikov, V. N. Kozhevnikov, M. Z. Shafikov, A. M. Prokhorov, D. W. Bruce and J. A. G. Williams, Inorg. Chem., 2011, 50, 3804; (b) P.-T. Chou, Y. Chi, M.-W. Chung and C.-C. Lin, Coord. Chem. Rev., 2011, 255, 2653.

11 (a) P.-H. Lanoë, C. M. Tong, R. W. Harrington, M. R. Probert, W. Clegg, J. A. G. Williams and V. N. Kozhevnikov, Chem. Commun., 2014, 50, 6831; (b) R. E. Daniels, S. Culham, M. Hunter, M. C. Durrant, M. R. Probert, W. Clegg, J. A. G. Williams and V. N. Kozhevnikov, Dalton Trans., 2016, 45, 6949.

12 (a) V. N. Kozhevnikov, M. C. Durrant and J. A. G. Williams, Inorg. Chem., 2011, 50, 6304; (b) S. Culham, P.-H. Lanoë, V. L. Whittle, M. C. Durrant, J. A. G. Williams and V. N. Kozhevnikov, Inorg. Chem., 2013, 52, 10992. 13 P. J. Hay, J. Phys. Chem. A, 2002, 106, 1634.

14 A. F. Rausch, L. Murphy, J. A. G. Williams and H. Yersin, Inorg. Chem., 2012, 51, 312.

15 For example: (a) D. N. Chirdon, W. J. Transue, H. N. Kagalwala, A. Kaur, A. B. Maurer, T. Pintauer and S. Bernhard, Inorg. Chem., 2014, 53, 1487; (b) S. Muhmel, D. Alpers, F. Hoffmann and M. Brasholz, Chem. - Eur. J., 2015, 21, 12308. 